\title{
The rise of food banks and the challenge of matching food assistance with potential need: towards a spatially specific, rapid assessment approach
}

\author{
Christopher M. Bacon ${ }^{1}$ (D) Gregory A. Baker ${ }^{2}$
}

Accepted: 14 March 2017 / Published online: 10 April 2017

(C) The Author(s) 2017. This article is an open access publication

\begin{abstract}
In the United States, food banks served an estimated 46 million people in 2015. A combination of government policy reforms and political economic trends contributed to the rising numbers of individuals relying on private food assistance in the US, the United Kingdom and other high-income countries. Although researchers frequently map urban food environments, this project is one of the first to map private food assistance and potential need at the census-tract scale. We utilize Geographic Information Systems, demographic data, and food assistance locations to develop a rapid assessment tool that could support food banks, pantries, soup kitchens, and government agencies that seek to answer the question of whether people with the greatest need have food distribution sites in close proximity. We define access based on distance and then calculate potential food insecurity using either poverty rates or a food insecurity index. We apply these methods in a case study analysis of Santa Clara County, California. Our findings suggest that food assistance distribution locations match the areas of potential need in more than $80 \%$ of urban census tracts. However, there are several potentially underserved locations and populations that could benefit from new food assistance operations. The poverty and index-based approaches show significant spatial overlap in mapped areas of high food insecurity and low access. The poverty only approach produces a higher estimate of food
\end{abstract}

Christopher M. Bacon

cbacon@scu.edu

1 Department of Environmental Studies and Sciences, Santa Clara University, 500 El Camino Real, Santa Clara, CA 95053, USA

2 Department of Management, Santa Clara University, Lucas Hall, Room 111D, Santa Clara, CA 95053, USA insecurity rates, is easier to calculate, and draws attention to the need to address poverty as a root cause of hunger.

Keywords Food security · Food assistance $\cdot$ Food justice $\cdot$ Poverty $\cdot$ Food environments $\cdot$ Geographic information systems (GIS) · Decision support

$\begin{array}{ll}\text { Abbreviations } \\ \text { ACS } & \text { American Community Survey } \\ \text { CT } & \text { Census Tract } \\ \text { FII } & \text { Food Insecurity Index } \\ \text { FPL } & \text { Federal Poverty Level } \\ \text { GIS } & \text { Geographic Information Systems } \\ \text { SCC } & \text { Santa Clara County } \\ \text { SNAP } & \text { Supplemental Nutrition Assistance Program } \\ \text { TFEAP } & \text { Temporary Food Emergency Assistance Program } \\ \text { UK } & \text { United Kingdom } \\ \text { US } & \text { United States of America } \\ \text { USDA } & \text { United States Department of Agriculture } \\ \text { WIC } & \text { Women, Infants, and Children Program }\end{array}$

\section{Introduction}

Although the vast majority of food insecure people live in the developing world, food insecurity remains a vexing problem in the United States (US) and many other industrialized countries, including Australia, Canada, and the United Kingdom (UK) (McIntyre et al. 2016). The United States Department of Agriculture (USDA) classifies a household as food insecure when "access to adequate food is limited by a lack of money and other resources" (Coleman-Jensen et al. 2014). Jensen wrote that despite "ample aggregate food supplies and relatively low food prices, many households do not have assured access to 
enough food to meet their dietary needs to lead active and healthy lives" (Jensen 2002, p. 1215). Households facing risks to their ability to access sufficient food rely on a wide range of coping strategies, which can include: the use of credit to buy food, eating less, skipping meals and participating in government or private food assistance programs. Although government food programs have historically assumed the primary role in attempting to alleviate food insecurity, in the last decade private food assistance led by food banks and/or local food pantries and soup kitchens emerged as a key source of food assistance in the US, Australia, UK, and elsewhere. Thus far, research analyzing food banks' management decisions and strategies used to reach those most in need have not kept up with this rapid expansion (González-Torre and Coque 2016).

The number of food insecure households in the US continues to remain high despite economic growth following the Great Recession of 2008. In 2014, 48.1 million Americans, representing $14.0 \%$ of US households, were classified as food insecure (Coleman-Jensen et al. 2014). This compares to 36.2 million Americans (11.1\% of the households) in 2007, the year preceding the Great Recession (ColemanJensen et al. 2014). The percentage of households classified as food insecure has declined only slightly from a high of 14.9\% in 2011 (Coleman-Jensen et al. 2014). Perhaps more disturbing is the number of food-insecure households with children. In 2014, almost one in five households with children (19.2\%) was classified as food insecure as compared to 15.8\% of households in 2007 (Coleman-Jensen et al. 2014). This trend is troublesome due to the negative health effects associated with food insecurity in households with children, including birth defects, cognitive problems, poor general health, and complications from oral health issues (Jyoti et al. 2005). These statistics remind us "No rich democracy matches the United States in the depth and expanse of its poverty. As of 2015, almost 50 million Americans lived below the federal poverty line" (Desmond 2015, p. 3).

Food banks operate very differently across the globe. In the US, Canada, and Australia, food banks largely operate to source food and funds so that they can distribute to food pantries and soup kitchens. In the UK, the Trussell Trust is the largest food bank. It sources food and directly distributes it through over 400 community food banks, which are similar to food pantries that operate in the US. To simplify terminology, specific reference to UK food banks will be called emergency food aid providers. Unlike in the US system, Trussell Trust emergency food aid providers operate a voucher and referral system prior to providing clients with access to nonperishable food distribution. This approach risks excluding certain individuals and reinforcing constructions of the deserving and undeserving poor (Williams et al. 2016).
In the US, food banks served an estimated one in seven people (more than 46 million) in 2014 (Feeding America 2014). As of 2013, the "4743 organizations included in Food Banks Canada's annual 'HungerCount' provided groceries to 833,098 people through food banks and local distribution centers, and 4,341,659 meals through soup kitchens, shelters, school breakfast programs, and other venues" (Food Banks Canada 2013 cited in Tarasuk et al. 2014, p. 1409). An analysis of trends over time shows that the reliance on food banks has expanded rapidly in Canada. In the UK, Oxfam reports that one in five people live below the poverty line, and rising costs of food and energy coupled with stagnant wages has contributed to the rapidly expanding presence of food banks. "In 2009-2010 Trussell Trust food banks [or emergency food assistance distribution centers] were operating in 29 local authorities across the UK; by 2013-2014, the number had jumped to 251 and food banks are now found in nearly every district of the UK" (Loopstra et al. 2015, p. 1).

The motivation for this research arose out of a discussion with local food bank managers regarding how well the food insecure population was served by food distribution agencies. Accessibility remains a challenge to many clients, especially when food assistance is difficult to obtain because of location, hours of operation, and/or transportation options (Tsang et al. 2011). People who go to food assistance sites must have the necessary time, energy, and knowledge to "know where to go and when, within a complex and constantly changing landscape of providers and other resources" (Miewald and McCann 2014, p. 544). Disability, age, illness, children, and the social stigma associated with welfare present additional barriers to access. Those without cars must find alternative ways to transport themselves to sites and carry food back from these locations. Such assessments are difficult for food banks in the US, since they act similar to a food wholesaler; they solicit donations of money and food and then distribute food to partner organizations (e.g., soup kitchens, food pantries, and other programs) that often operate like food retailers by providing food directly to clients. Not only do food banks have a limited relationship with the population they serve, but they also lack direct control over the distribution of the product. Our conversations led to a discussion of the potential for using of geographic information systems (GIS) to assess how well non-governmental food assistance programs can address the proximity dimensions of access in serving food insecure populations.

The objective of this study is to assess how well a local food assistance organization serves its clientele from a geographical perspective. Specifically, the research question is: do the areas with the highest concentration of people who are likely in need of food assistance have food distribution sites in close proximity? Prior to responding to 
this question, we examine the broader political economic context contributing to the rise of food banks, and assess the contributions and limits of recent studies mapping food access. After describing the methods and presenting our results, we share a future research section that draws on recent scholarship in human geography to critically reflect on the role of research and private food assistance as part of efforts to both improve immediate responses to food insecurity, and foster innovations that address the persistence of poverty and malnutrition.

\section{Food entitlement programs and the rise of food banks in the US}

In the US, there are a variety of governmental programs to assist low-income families in responding to the risk of food insecurity (Schmidt et al. 2013). The largest of these programs is the Supplemental Nutrition Assistance Program (SNAP), often referred to as Food Stamps. In 2014, 46.5 million Americans residing in 22.7 million households received benefits from SNAP, totaling \$74.1 billion (USDA and Food and Nutrition Service 2015). Although SNAP does not meet all food needs, rigorous research shows that it remains one of the most important elements of the social safety net and is the second largest anti-poverty program for children in the US (Hoynes et al. 2017). Other major governmental food assistance programs include the National School Lunch Program (30.4 million children and $\$ 12.7$ billion in benefits), the School Breakfast Program (13.6 million children and $\$ 3.7$ billion in benefits), and the Women, Infants, and Children Program (WIC), (8.3 million recipients and $\$ 4.3$ billion in benefits), (USDA and Food and Nutrition Service 2015).

Nutrition assistance programs began during the Great Depression era when breadlines coincided with collapsing farm-level prices for many commodities, including wheat, corn, and cotton. The Agricultural Adjustment Act of 1933 directed the federal government to pay farmers to reduce agricultural production. Surplus commodities purchased by the federal government were then distributed through hunger relief agencies. A few decades later, during the presidential campaign debates of 1960 , candidate John F. Kennedy brought the issue of hunger in the US from the margins of food policy debates to the forefront. After Kennedy's election, his administration developed policies and programs to address the growing hunger problem. These programs were modified and expanded by subsequent administrations. Two notable programs that endure today are the food stamp program, or SNAP, and the WIC program. Agricultural subsidies and food aid, both authorized by the Farm Bill, have survived in part because of support from a rural-urban coalition with rural legislators advocating for farm price support programs and urban legislators supporting nutrition assistance programs. While the nutrition assistance programs have contributed to hunger alleviation, government food distribution programs largely exclude nutritionally important foods, such as fruits and vegetables because they focus on the distribution of surplus commodities such as dairy and wheat.

The passage of the US's Temporary Food Emergency Assistance Program (TEFAP) in 1983 coupled with a reduction in SNAP benefits in subsequent years led to the emergence of a national private food assistance network consisting of food banks and food pantries (Cabili et al. 2013). Prior to TEFAP, food assistance was provided by 13 locally operated food banks that relied on local food donations to supply local churches, and charitable organizations (Daponte and Bade 2006). Some 20 years later, the combination of policy reform, civil society initiative, and economic change contributed to the emergence of a national network of more than 230 food banks (Gottlieb and Joshi 2013, p. 94; Feeding America 2014). Compared to past food assistance programs, today's programs have started to develop a stronger focus on nutrition. Moreover, donations of food from producers, processors, wholesalers, and retailers have increased greatly because of tax incentives available through the program (Daponte and Bade 2006).

The aforementioned government policy changes, combined with the 2007-2008 financial crisis in the US, stagnant wages, rising costs of living, underemployment, and unemployment spurred the rise of non-profit food banks in the US and other high-income countries (Bazerghi et al. 2016; Lambie-Mumford and Dower 2014). Data for nongovernmental food assistance in the US is difficult to verify because it is provided by multiple agencies with no central reporting. Nonetheless, we can get some idea of the importance of non-governmental food assistance by looking at the data from Feeding America, the largest non-governmental, hunger-relief agency in the US. Feeding America oversees a network of over 200 member food banks that represent approximately $80 \%$ of the food banks in the US (Feeding America 2014). In 2014, Feeding America reported that their network of food banks and over 60,000 partner agencies, including food pantries, soup kitchens, and meals on wheels programs, provided 3.3 billion meals to more than 46 million low-income individuals (Feeding America 2014). Although governmental and non-governmental agencies provide substantial support for low-income people, the problem of food insecurity persists. Feeding America estimates that as of 2014, an additional 8.6 billion meals were needed to fully meet the needs of Americans.

Studies about the rise of private food assistance have documented long-term dependence on 'temporary' emergency food assistance (Paynter et al. 2011), explained the role of food pantries in providing key benefits that respond 
to the needs of the changing face of hunger (Will and Milligan 2015), and critically analyzed the political and economic limits of this approach (Poppendieck 1999). Although food bank programs can help connect clients directly with government led programs, such as SNAP, sometimes these links are not established. Researchers also note that this model of food access limits the ability of citizens and residents to claim what many consider a human right to food entitlements when the primary source of food assistance is a private non-profit enterprise and not a government agency (Daponte and Bade 2006). In a recently published critical review of the scholarship on food banks, McIntyre and colleagues group the 33 articles they analyzed into those that focus on operational challenges (e.g., effectiveness and accessibility) and those that focus on the broader concerns of poverty and exclusion (e.g., indignity and invisibility of hunger) (McIntyre et al. 2016). The increasing size and scope of private food assistance networks suggests the need to approach all dimensions of this challenge, for a better understanding of the impact of these programs, an analysis of how they interact with public food assistance programs, and the development of strategies to more effectively target support.

\section{Mapping local food insecurity and access to food assistance distribution}

To develop a rapid assessment approach for mapping local household food insecurity, we started by asking: what are the proximate correlative factors that influence the predominance of food insecurity in high-income countries? A large-scale national study of the state and county level determinants of household food security in the US offers a starting point for our analysis (Gundersen et al. 2014). This study integrated the results of household surveys using the USDA's battery of core food security questions with demographic data from the US American Community Survey (ACS), finding statistically significant correlations linking poverty, unemployment, and home renting (vs. ownership) to higher levels of food insecurity (Gundersen et al. 2014). The Gundersen study's model also found statistically significant fixed effects related to the year of analysis, which generally correlate with fluctuations in the US economy, and the state of residence, suggesting the need for attention to the local determinants. This study was one of the first to move beyond the statewide summaries that aggregate the number of food insecure households to develop a countyby-county assessment. Another study from the Trussell Trust, the Church of England, and the charities Oxfam and Child Poverty Action Group found that food bank users in the UK were more likely to live in rented accommodations, be single adults or lone parents, be unemployed, and have experienced a "sanction," where their unemployment benefits were cut for at least one month (Loopstra et al. 2015, p. 1, citing; Perry et al. 2014).

Our efforts to develop a procedure to map the patterns of access among potentially food insecure households and match them to the locations of food assistance benefit from a large body of existing research using GIS to analyze the spatial patterns of access to healthy food and food environments (Feagan et al. 2007; Larson et al. 2009; Hirsch and Hillier 2013; USDA 2015). Several of the pioneering studies in this literature sought to correlate a population's weight and health status with demographic data and proximity to supermarkets and fast food outlets generating an evolving debate about urban food environments and 'food deserts' (Gordon-Larsen et al. 2006; Larson et al. 2009). These studies and the USDA's Food Access Research Atlas (USDA 2015) draw buffers around supermarkets (0.5 miles or 1 mile in urban areas and 10 miles in rural areas) and then use distance to the nearest full-service supermarket as a key proximity-based indicator of access, which is then combined with poverty levels to identify areas with high poverty and low access to more affordable fresh fruits and vegetables (Gordon-Larsen et al. 2006; Gordon et al. 2011).

\section{Food access mapping limits and the challenges of everyday foodscapes}

Although scholars conducting food desert research have produced many quantitative studies analyzing spatial patterns of urban and rural access to nutritious food (McKinnon et al. 2009) and recently extended this approach with studies that focus on residents' transportation patterns in low food access areas (Hirsch and Hillier 2013; LeClair and Aksan 2014), some scholars and food justice activists have critiqued food desert studies. These critiques highlight the way that conventional food desert studies remained rooted in a supply side perspective that relies almost exclusively on the use of quantitative and geospatial methodologies to understand obesity and food insecurity (Short et al. 2007). This methodological focus often leaves these studies silent on how racial and ethnic differences relate to the subjective lived experiences of community members experiencing food poverty, food preferences, and broader aspirations for food system and community change (Alkon et al. 2013; Shannon 2013).

Shannon argues that by defining food deserts "through their absences" researchers and policy makers are using a deficit model that neatly bounds the problem in a way that generally leads to one "solution" which is to open a supermarket in a spatially optimized location (Shannon 2013, p. 11). While the presence of supermarkets in certain places (e.g., parts of Detroit or Chicago's South 
Side) could increase low income residents' proximity to fresh fruits and vegetables at prices below those offered in most corner stores, a supermarket-only solution to food insecurity and obesity does not address root causes. Although in some cases these mapping approaches offer a useful starting point, this approach neither recognizes how relationships shape both place (Goodman 2016) and food security (Drèze and Sen 1989), nor does it address how people shop and access food through time (Widener and Shannon 2014). Critiques of food desert studies' failure to develop a sophisticated analysis of the causal factors that shape patterns of obesity and food insecurity note that these studies often ignore the influence of exposures to environmental pollutants, poverty, stigma and social marginalization, while some of the deeper critiques also raise broader questions about the governmental regulation of urban bodies and spaces, as well as the idea of an 'obesity epidemic' (Guthman 2011). Collectively the critical approach has generated new avenues for research, questioned simplified policy responses to complex problems of food insecurity and access to healthy foods (Guthman 2011), and helped to inspire a more sophisticated series of urban food access and mapping studies (Hirsch and Hillier 2013; Widener and Shannon 2014).

Qualitative and mixed methods studies of foodways explain urban food insecurity and the broader challenges of malnutrition and poor access to affordable nutritious food, as they analyze everyday experiences of sustenance in ways not captured in purely quantitative mapping approaches. A range of largely qualitative studies offer conceptual insights into how culture, age, class, race, ethnicity, gender, and other dimensions of identity relate with nature and society through food production and consumption (Goodman 2016; Alkon 2013). Many of these studies explore how urban food insecurity links to the broader political economic forces as they relate to issues, such as uneven development, displacement, homelessness, welfare reform, and the shifting geographies of social welfare programs (Deverteuil 2015; Allard 2008). Other studies focus on the injustices and contradictions associated with modern production-oriented food systems e.g., developing case studies showing how low farm worker wages and uncertain immigration status perpetuate food insecurity (Minkoff-Zern 2014a). Finally, some scholars further this critical analysis as they raise pressing questions about how racial and food politics relate to food security assistance efforts that fail to take seriously cultural preferences and local knowledge, aiming to educate food insecure populations on how to cook or bring "good food to others" (Guthman 2008), instead of recognizing the local knowledge and culturally rooted responses among food insecure communities as one of the key starting points for developing responses (Bacon et al. 2014; Minkoff-Zern 2014b), or analyzing the root causes of poverty as it relates to hunger (Lambie-Mumford 2013; Hoynes et al. 2017).

Although not included in our study, an important complementary area of research considers the broader experiences of food poverty, and the common coping and access strategies that individuals and families use in their daily efforts to secure food beyond what is available in food pantries or through government programs, which generally provide insufficient food during lean times. A recent study of food assistance in the UK, conducted interviews with food bank patrons and found that visiting emergency food providers is often one of the least preferred coping mechanisms due to stigma and shame (Purdam et al. 2015), and similar results were also found in an ethnographic study conducted in the US (Greer et al. 2016). The UK-based study also shares the voices of those mobilizing coping mechanisms that range from relying on family and friends to purchasing of lower quality "cheap" foods, noting that "another food bank user commented: "I buy the cheapest food in the supermarket ... and make it last. I wait by the reduced section in the supermarket. I make the food bank food last all week' (female, aged 63)" (Purdam et al. 2015, p. 9-10). Feeding America recently supported another qualitative study that garnered news headlines as it identified the "impossible choices" faced by teenagers likely to experience food insecurity in ten major US cities. Key findings include: the presence of widespread food insecurity in this population segment, persistence of stigma around hunger and actively hiding it, teens overwhelmingly prefer to earn money in a formal job, and that when faced with acute food insecurity, teens in eight of the ten communities said that youth engage in criminal behavior, ranging from shoplifting food directly to selling drugs and stealing items to resell for cash (Popkin et al. 2016). Regardless of methodological focus, these recent studies concur that the depth and scope of the food insecurity in modern industrial countries could be larger than the government estimates suggesting the importance of expanded support and targeted food assistance.

\section{Methods}

Our research focuses on one key area of food assistance research, the challenge of determining whether existing food assistance distribution efforts provide adequate geographical coverage to meet the need for food assistance. We focus on the challenge of improving food assistance distribution due to interest from food bank managers. Moreover, we could not identify published research in which mapping approaches were used to match food assistance provision to a comparative analysis of different 
measures of food insecurity at the local level. Government and private food assistance efforts could benefit from studies that map food insecure populations and the location of soup kitchens, food pantries and other points of access by using this or a similar method to rapidly assess and distinguish vulnerable neighborhoods and reach people who may be struggling the most.

\section{Study site and data sources}

We collaborated with a local food bank, Second Harvest Food Bank of Santa Clara and San Mateo Counties (referred to as either "Second Harvest" or the "food bank" in the remainder of the paper), located in the San Francisco Bay Area of Northern California. Second Harvest provided data specifying the location and quantities of food distributed through different programs in 2009. Our primary source of household data for this analysis is from the US Census ACS 5-year estimates of poverty and demographic data, for years 2010-2014 (US Census 2015). We decided to focus on SCC, because it is a populous, largely urban county in close proximity to the researchers with several high-income areas and pockets of low-income households.

Second Harvest provided geocoded data on food distribution locations. Precise numbers are not available, but Second Harvest estimates that it provides the great majority, over $90 \%$, of all food assistance in the two counties that they serve, Santa Clara and San Mateo Counties. We focused on food pantries and soup kitchens since more than $80 \%$ of the food distributed by Second Harvest is distributed through these two channels. Furthermore, this type of food assistance is targeted at the entire family as opposed to food assistance that aims to help a specific group, such as children or senior citizens. Food pantries provide bags of groceries; soup kitchens serve meals prepared from donated food that they receive.

SCC, one of nine counties in the San Francisco Bay Area, is located at the southern end of the San Francisco Bay. The county and surrounding areas are commonly referred to as Silicon Valley. The region is ethnically diverse with a population that is $34.9 \%$ Asian, 33.3\% Non-Hispanic White, 26.6\% Hispanic, and 2.9\% African American (US Census Bureau 2014a). Although the region has a high median household income of approximately $\$ 90,000,10.2 \%$ of the population lives below the federal poverty threshold (US Census Bureau 2014b) and Feeding America, using a formula developed by Gundersen, estimates that $12.1 \%$ of the population was food insecure in 2013, which was down from their estimate of 13.4\% in 2011 (Feeding America 2015).
A comparison of two strategies to map food insecurity and access to assistance

We developed a comparative analysis that uses both poverty and a food insecurity index (FII) as two ways of measuring and mapping food insecurity. We started with a map of poverty rates (see Fig. 1). Although the income standard for most federal food nutrition programs is $185 \%$ of the federal poverty level (FPL), Second Harvest and the State of California's use incomes that are $200 \%$ of the FPL due to the extremely high cost of living in the Bay Area. We used $200 \%$ of the FPL in determining whether a household was considered food insecure, and we will continue to use $200 \%$ of the FPL to describe an individual who is low-income or in poverty in this article. For each census tract we calculated the percentage of the population that was at or below $200 \%$ of FPL and then divided the census tracts into quintiles based on the ordering of these percentages.

In the second step of our analysis, we incorporated the location and indicators of access to Second Harvest's network of food pantries and soup kitchens (see Fig. 2). Before performing this analysis we used US Census maps to identify rural and urban areas (see "Technical appendix"). In urban census tracts, we used the same buffers suggested by the USDA (2015), using GIS to draw 1-mile buffer zones around each food pantry and soup kitchen to indicate the area that is within close proximity. The 1-mile buffer is commonly used to assess the proximity dimension of food access to a full service supermarket in urban areas of the US (USDA 2009, 2015; Wilde et al. 2014). To determine access for rural residents we used a 10-mile buffer, which the USDA uses as the minimum distance to a supermarket when identifying unfavorable rural food environments (USDA 2009; Wilde et al. 2014). When we drew the 10-mile buffers they covered all rural areas in SCC, and thus they were omitted from Fig. 2. The 1-and 10-mile buffers were used to calculate accessibility to food pantries and soup kitchens by applying the "use ratio policy" in ESRI's Arcmap 10.2. This allowed us to analyze the percentage of each census tract's area that is covered by the buffer and assign the same percentage to its population value as well as that portion of the population living at or below $200 \%$ of the FPL (Harder et al. 2013).

The third step develops a poverty-based assessment of food insecurity, and employs it to identify areas of concern-specifically census tracts with high poverty and low access to food assistance distribution locations (see Fig. 3). High poverty is defined based on the natural breaks in the poverty data (see Fig. 1), which represents census tracts with $22.2 \%$ or more of the population at or below $200 \%$ of the FPL. For urban areas, the access to food distribution sites was calculated based the distances developed in step two. We define access based on proximity using USDA 
Fig. 1 Poverty levels, by census tract in Santa Clara County. The map in $a$ shows the location of SCC in California. The large, low-density population area shown in $b$ is omitted from subsequent analysis. (Sources US Census, ACS 5-year estimates 2010-2014)

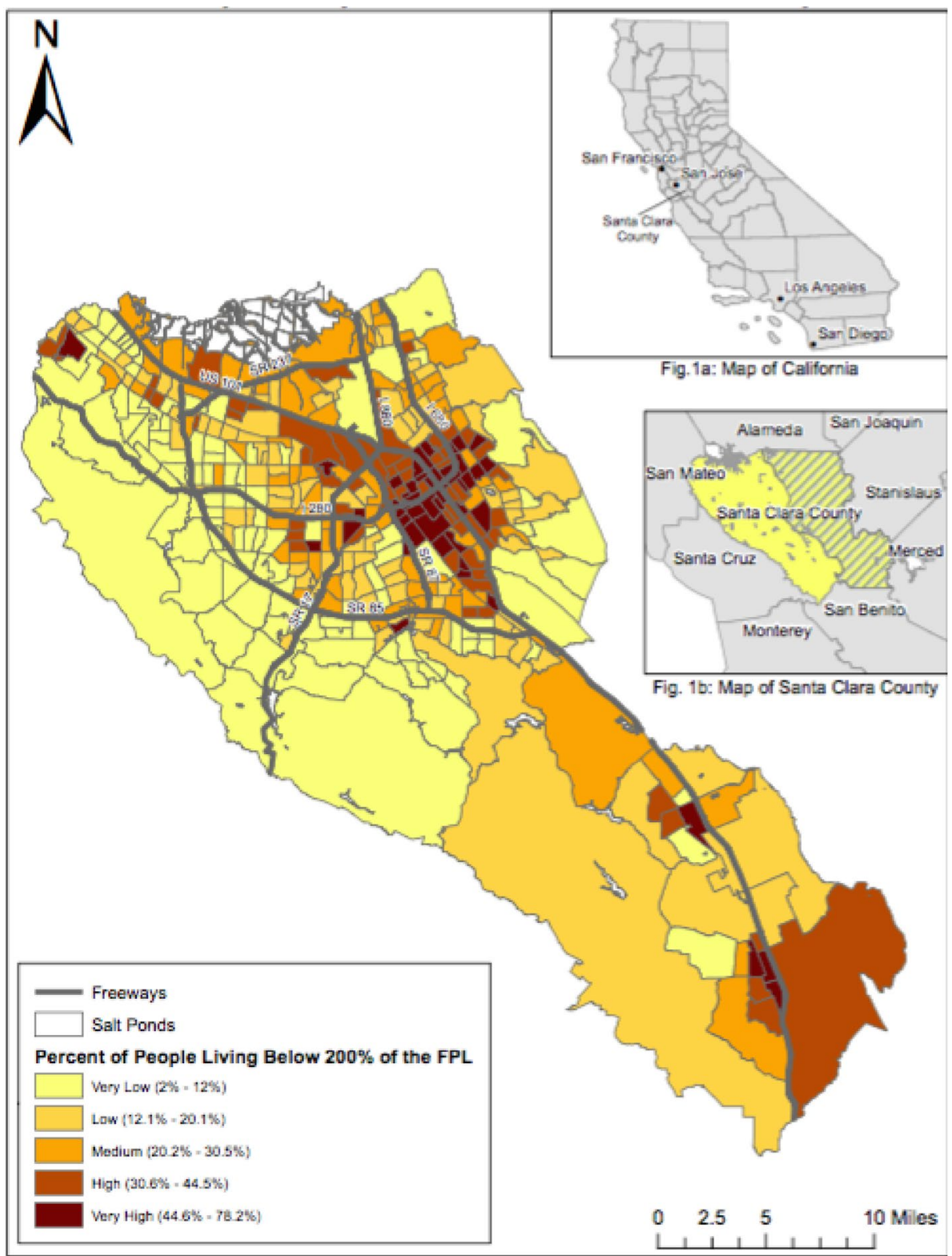

criteria for Food Access Research Atlas such that low access $=67 \%$ or more of the census tract area is outside of the 1-mile buffer around food assistance distribution locations. Some access equates to $34-66 \%$ of the census tract area lying outside of the 1-mile buffer around food assistance distribution locations. Good access represents $33 \%$ or less of the census tract area lying outside of the 1-mile buffer around food assistance distribution locations (USDA 2015). Access for rural census tracts is calculated in the same manner except that the buffer zone is 10 miles rather than 1 mile.

The next three steps involve creating a Food Insecurity Index (FII) that represents the percent of individuals within a census tract that are potentially food insecure. To do this, we drew on the national study regarding the proximate determinants of food insecurity (Gundersen et al. 2014) to identify the independent variables that correlate significantly with reported levels of household food security. The most important county- and state-level variables in the model are poverty, unemployment, and the percentage of households that are occupied by renters. ${ }^{1}$

\footnotetext{
${ }^{1}$ In Gundersen's model (see Gundersen et al. 2014 and Gundersen et al. 2015), unemployment has a higher coefficient than poverty, and the other statistically significant correlates with food insecurity include constant, and fixed effects for different states and years.
} 
Fig. 2 Map of SCC poverty levels and food assistance distribution sites with buffer zones, by Census Tract. (Sources US Census 2010; Second Harvest Food Bank of Santa Clara County and San Mateo Counties 2013)

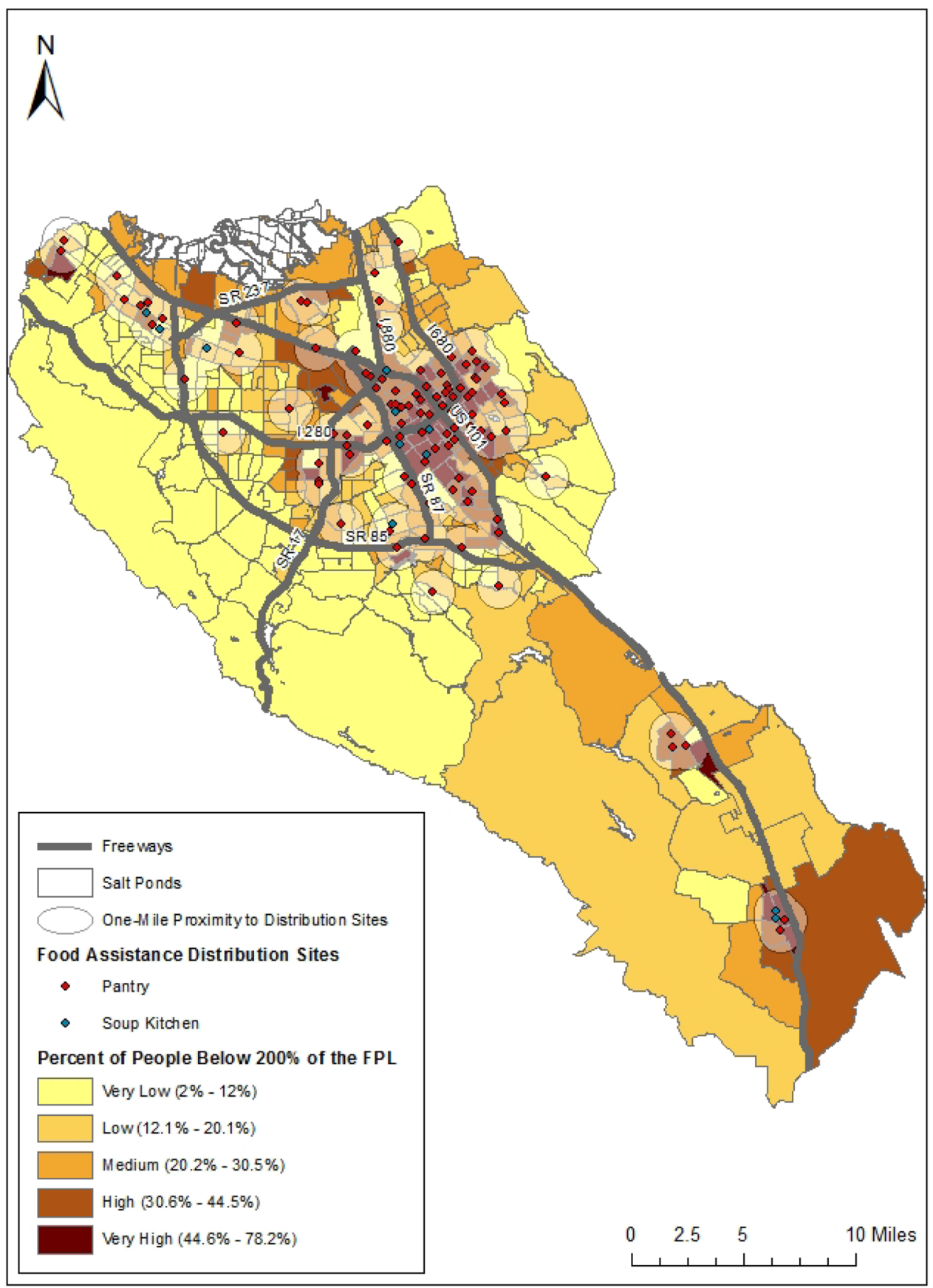

We then weighted these variables based on the literature suggesting that poverty is the key driver of food insecurity, and their perceived importance in the local context as reported by Second Harvest managers.

To calculate the FII for each census tract, we multiply the percent of people in a census tract who are at or below $200 \%$ of the FPL (Poverty\%) by 50, the percent of people in renter-occupied units (Rent\%) by 10 , and the percent of households with one or more unemployed member (Unemployed\%) by 40 and divide by 100 (Eq. 1). ${ }^{2}$ These calculations were made for each census tract $(c t)$ (see equation below) and then the data were displayed to show the distribution of food-insecure areas

\footnotetext{
$\overline{2}$ The algorithm that Feeding America (Gundersen et al. 2015; Feeding America 2016) uses for estimating food insecurity at the state and county levels as well as the most recent data for 2014 was unavailable at the time of writing.
} 
Fig. 3 High poverty and low access areas. High poverty is defined as census tracts (CT) with $22.2 \%$ or more of the population at or below $200 \%$ of the FPL (see Fig. 1). The map includes high poverty tracts only. Low access indicates $67 \%$ or more of the CT area is outside of the 1-mile buffer around food assistance distribution locations; Some access indicates 66 to $34 \%$ of the census tract area is outside of the 1-mile buffer around food assistance distribution locations. Good access indicates $33 \%$ or less of the CT area is outside of the 1-mile buffer around food assistance locations. (Sources Own calculation using US Census, ACS 5-year estimates 2010-2014; Second Harvest Food Bank of Santa Clara and San Mateo Counties 2013)

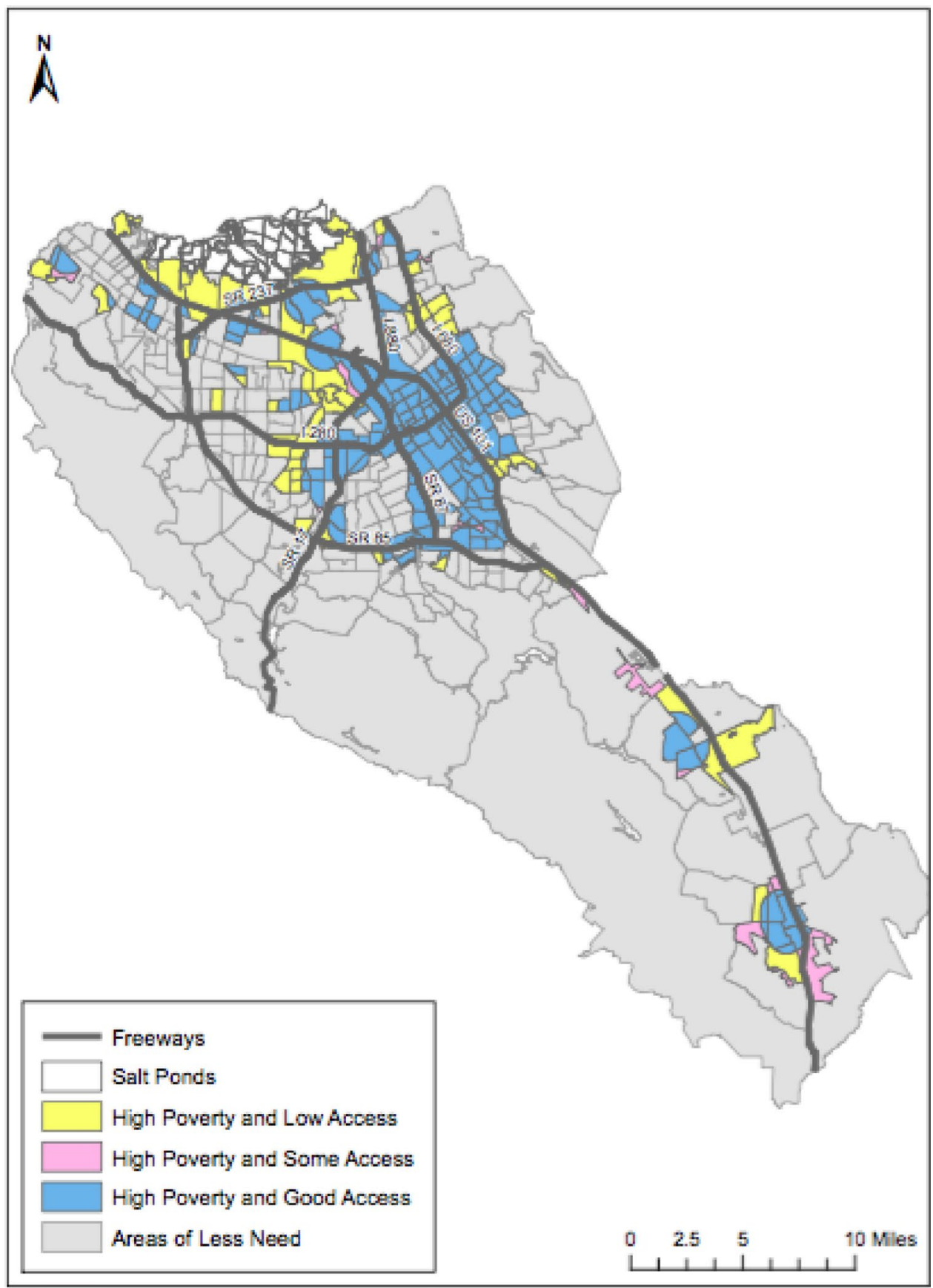

within the county together with the location of food distribution sites (Fig. 4). (e.g., low, some, and good access) described in the povertybased analysis for both urban and rural areas. These data

$\mathrm{FII}(\mathrm{ct})=\frac{[50 \times \text { Poverty } \%(\mathrm{ct})+40 \times \text { Unemployed } \%(\mathrm{ct})+10 \times \text { Rent } \%(\mathrm{ct})]}{100}$

The seventh step involved using the FII to identify areas of high food insecurity and low access (see Fig. 5). We defined access based on the percentage of the census tract covered by the buffer areas using the same three levels were displayed using ArcGIS together with the SHFB food assistance distribution sites and the 1-mile buffers (for urban areas) as previously described. High food insecurity census tracts were defined as those in which the 
Fig. 4 Food Insecurity Index and the location of food assistance distribution sites. (Sources Own calculation using US Census, ACS 5-year estimates 2010-2014; Second Harvest Food Bank of Santa Clara and San Mateo Counties 2013)

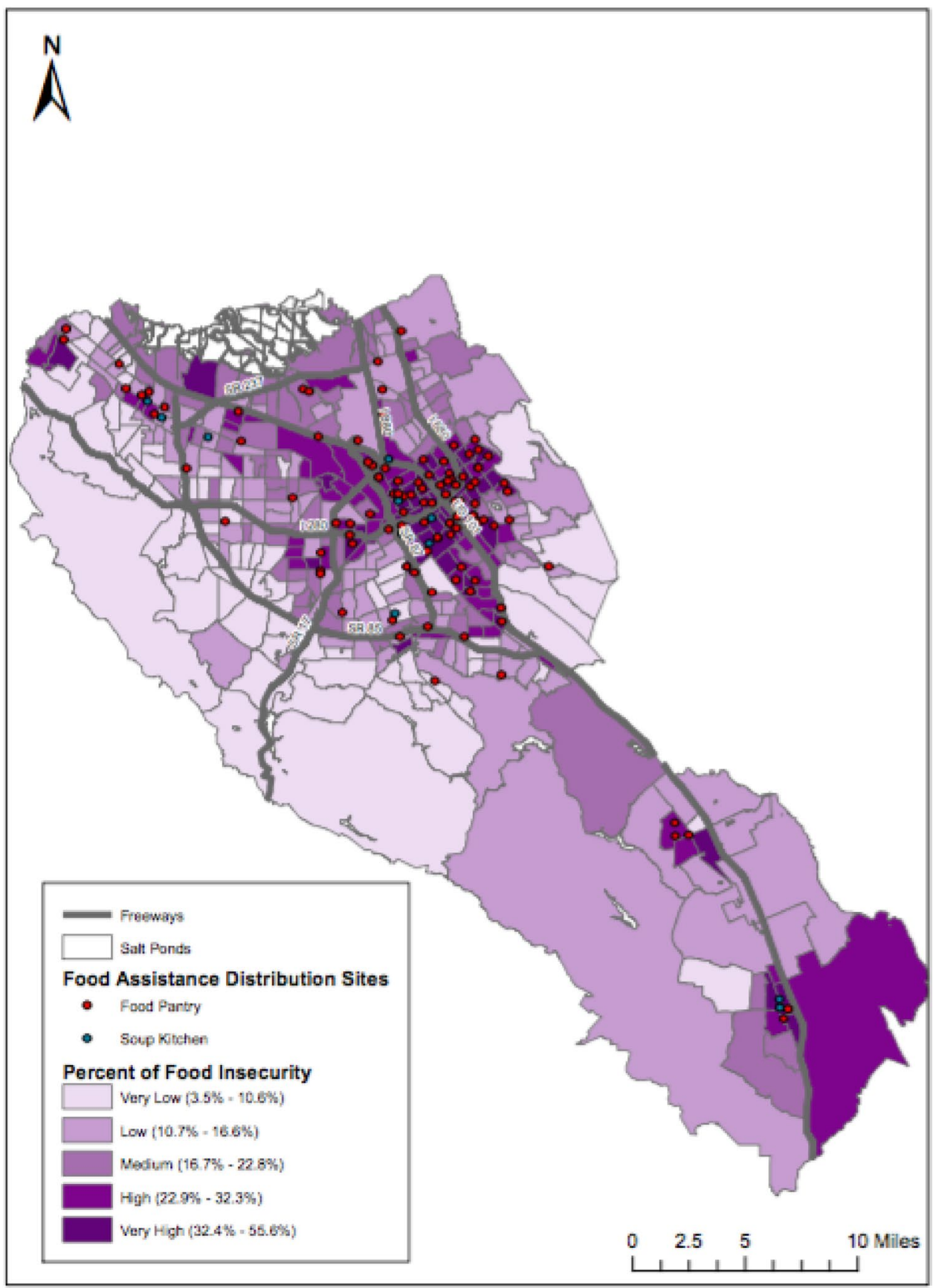

index-based calculation found that at least $16.7 \%$ of the population within the tract is food insecure. We only presented the data for the urban census tracts, since the rural ones include a 10-mile buffer around the food distribution site and thus are fully covered.

Finally, we compare the results generated using the poverty-only score to those using the FII (Fig. 6). To do this, we identified the census tracts with low access to food distribution sites that had either a high poverty incidence or a high FII score. We then developed an overlay analysis that identified the areas of low access that had both high poverty and a high percentage of potential food insecurity as well as those areas of low access that had only a high poverty or a high FII score.

\section{Limits of this study}

There are several limitations to this research. First, although we have good information regarding population characteristics and the provision of food assistance, the information is not complete, and is subject to change. Regarding the food distribution sites, the food bank 
Fig. 5 High Food Insecurity Index Scores and low food assistance access areas. High food insecurity in this context refers to census tracts in which we estimate that $16.7 \%$ of more of the population is food insecure (USDA 2015). (Sources Own calculation using US Census, ACS 5-year estimates 2010-2014; US Census 2010; Second Harvest Food Bank of Santa Clara and San Mateo Counties 2013)

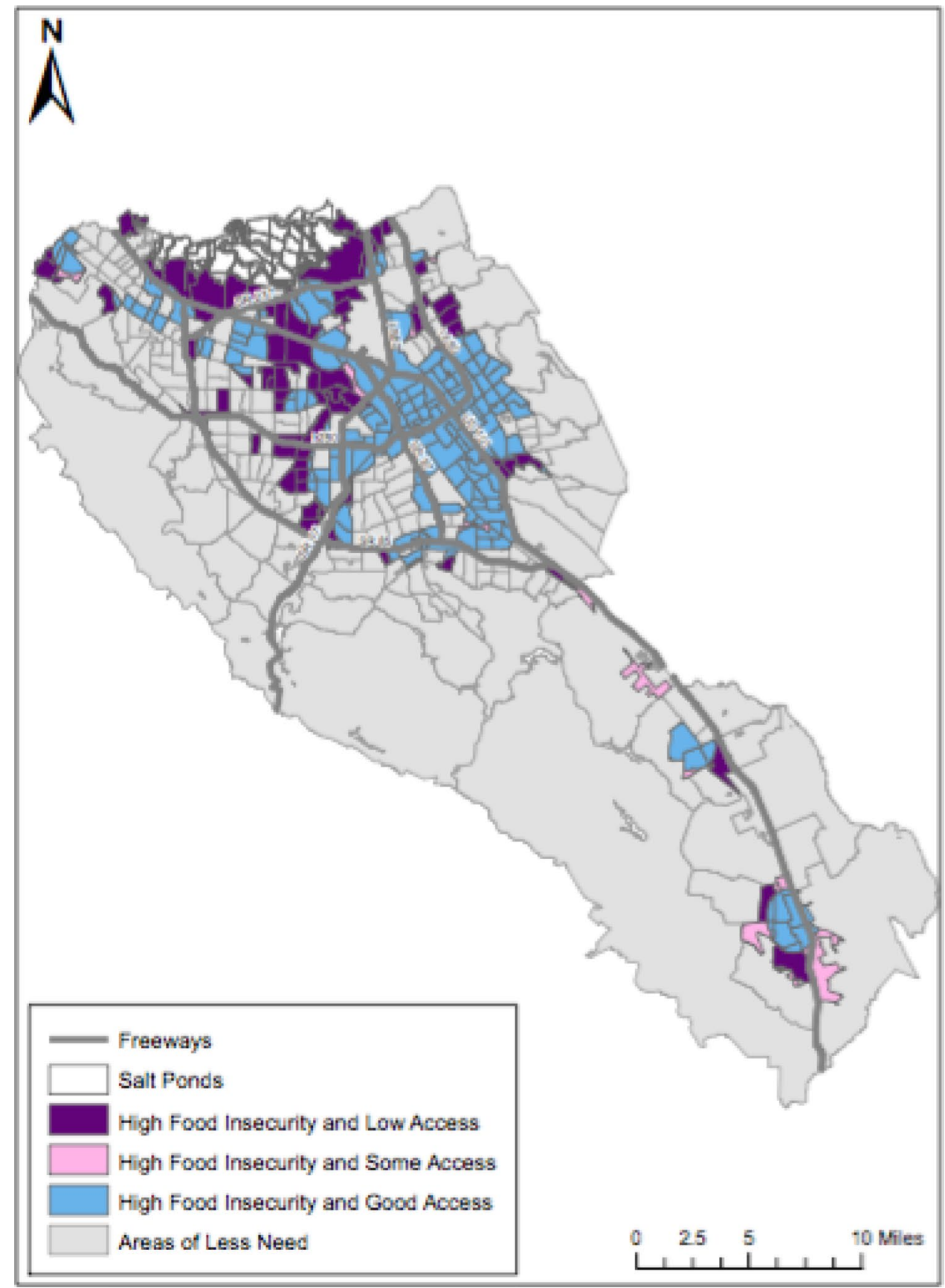

estimates that it provides over $90 \%$ of the food distributed to low-income people in SCC. Information on other sources is lacking. Regarding the demographic statistics, we rely on US Census data, which is generally regarded as high quality, but is not perfect. This is particularly true of the population in which we are interested, the poor. With a large immigrant population, many of whom are undocumented, there is the likelihood that this group will be undercounted and the location of their residences unknown. Furthermore, frequent moves are characteristic of the low-income population as they constantly strive to find housing in an area that has become increasingly unaffordable. The homeless population is another marginal group not included in mapping approaches that rely on Census data. The number of temporary homeless individuals is very high in this volatile housing market. An in-depth study found that in the 6 years from 2007 to $2012,104,206$ individuals experienced homelessness in SCC (Flaming et al. 2015, p. 2). Current estimates suggest that there are 7500 homeless individuals on any given night, of which about 2500 are chronically homeless (http://destinationhomescc.org/), and a point in time 
Fig. 6 Comparison of Food Insecurity Index versus poverty assessment. This is an overlay analysis that compares the areas of high poverty and low access versus areas with high FII scores and low access. (Sources Own calculation using data from US Census, ACS 5-year estimates 2010-2014; Second Harvest Food Bank of Santa Clara and San Mateo Counties 2013)

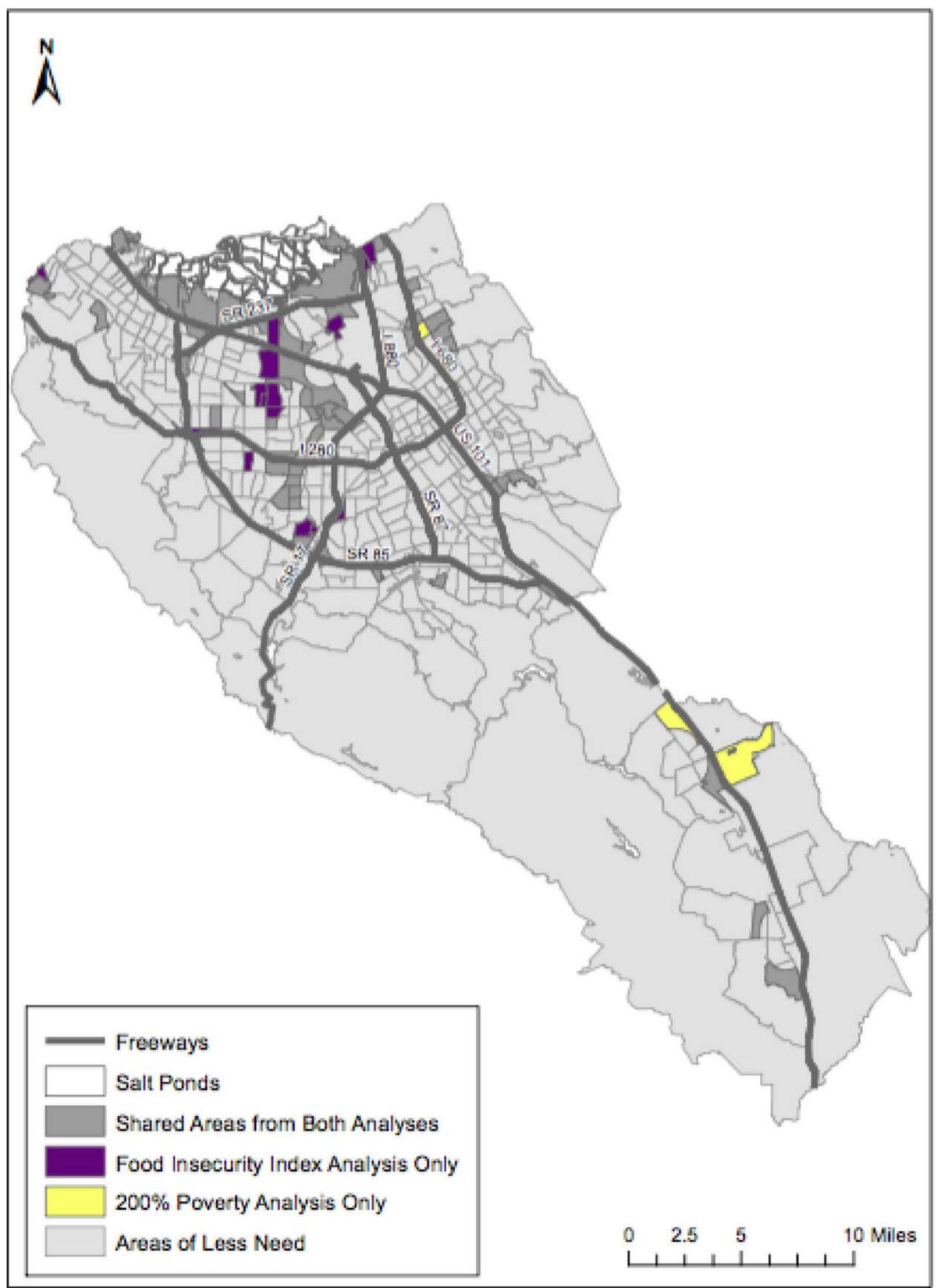

count found 6556 homeless individuals in SCC on January 27 and 28, 2015 (Applied Survey Research 2015).

One of the key assumptions that we make in developing the maps is that the overall population as well as the lowincome population is evenly dispersed within each census tract. For geographically small census tracts, this is not an issue; however, for large area census tracts, the issue may be significant. When we see one food distribution site in a census tract that stretches several miles from one end to another, the count of low-income residents that live near (or far) from a food distribution site depends on an assumption of population distribution. In these cases, as well as for some urban areas, more information is needed at the neighborhood level to make a determination as to whether those requiring food assistance are well served.

Other limitations of this study include our definitions of food insecurity or need (200\% of the FPL, unemployment, and house renting), distance as a proxy for access to food assistance, and the study's focus on one county. In choosing the criteria we necessarily omitted factors such as federal and state assistance, annual variability, access to transportation, and actual travel activity patterns, all of which 
impact need and access to food assistance sites. In future research, these screening approaches should be validated and refined using data collected from representative samples using the USDA's food security survey questions. The research was conducted in one urban county. To be generalizable, the study should be replicated in a diverse set of counties across the US.

\section{Findings}

In the following paragraphs we present the results of our analysis and discuss our major findings. We examine both the poverty-based assessment of food insecurity and the more robust assessment that also includes unemployment and the incidence of renting (vs. home ownership) and discuss the implications for identifying areas that may be underserved by food assistance distribution sites.

\section{Poverty-focused food security assessment}

Figure 1 depicts the poverty levels by census tract in SCC. The quintile representing those areas that are least impoverished have $2-12 \%$ of the population at or below $200 \%$ of the FPL, whereas the quintile containing census tracts with the highest levels of poverty have between 44.6 and $78.2 \%$ of the population at or below the $200 \%$ level. We do not include the mountainous region in the eastern portion of the county that has a very low and sparsely populated population. The areas with the highest levels of poverty are concentrated along the Highway US 101 corridor, which runs from the southeast corner to the northwest part of the county. These areas correspond to the lowest income areas of San Jose, Santa Clara, Sunnyvale, Mountain View, and Palo Alto. There is also a large cluster of low-income census tracts in what is known as East San Jose, which is centered near the junction of Highway US 101 and Interstate 680 (see Fig. 1).

Figure 2 adds point locations for pantries and soup kitchens. It is apparent that these food distribution sites are concentrated in East San Jose, also a high poverty area. Food assistance sites are much more dispersed in other areas of the county. The spatial patterns in this figure show that the current distribution of food assistance locations appears to be meeting the expected need in large areas of the county. Figure 2 adds 1-mile buffer zones around the food distribution sites, which help to assess how well the areas of greatest poverty are served by the sites providing food assistance.

For the most part, we observe that people living in the areas with the highest poverty levels live in close proximity to food assistance distribution centers. In Fig. 3, we develop an analysis that focuses on high poverty census tracts, defined as those in which more than $22 \%$ live below $200 \%$ of the FPL. These census tracts represent about $24 \%$ of those in the county, and most of them (61.1\%) have good access (shaded in blue) or at least some access (pink) to a food distribution site. If we extend this combined poverty and proximity analysis to all 371 census tracts in the county, including those with lower poverty rates, we find that $85 \%$ of SCC is either well served by food assistance distribution locations or has relatively low poverty rates.

The maps in Figs. 2 and 3 offer guidance to decision makers at the food bank and those who distribute food to the needy. To identify potentially underserved populations, we focused on urban census tracts that are both high-poverty and low access (see Fig. 3 for areas shaded in yellow or pink). In all of the rural census tracts, significantly less than $20 \%$ of the population lives farther than 10 miles away from a food distribution site, suggesting that the rural census tracts are currently well served based on the criteria for rural census tracts. However, areas of potential need persist in urban areas. We calculated that $38 \%$ of the low-income census tracts had low access to SHFB food assistance. This suggests that there is a need for greater access to food distribution in these areas of the county.

Furthermore, our study identified several potentially underserved regions using the poverty-based food insecurity assessment (see Fig. 3). These regions include the southern US 101 corridor near the cities of Gilroy and Morgan Hill, as well as a generally contiguous group of census tracts that lie west of Interstate 880 and State Road 17 extending from the northern central border of the county in the city of Santa Clara to west San Jose and the intersection of State Roads 85 and 17. A third potentially underserved area can be found in the northern portion of the county often referred to as East San Jose, which is generally east of Interstate 680 and US 101. Also, in the northwestern part of SCC between 101 and 280, an area that has a relatively high concentration of low-income people with no food assistance site nearby is located in Palo Alto. Although East Palo Alto is one of the well-known highpoverty and low-employment areas in the Bay Area (Benner and Karner 2016), this result could also be influenced by the "Stanford anomaly," suggesting that some, if not many, of the low-income members of the community are students, who may have additional support from relatives or elsewhere. It is interesting to note that food pantries have recently opened on many university campuses across the US (Nellum 2015).

\section{Food insecurity index assessment}

After conducting the poverty-based analysis, we developed the Food Insecurity Index (FII) and mapped the results of this alternative approach. The progression of Figs. 1 and 2 
explains the steps involved in developing this index, shown in Fig. 4. The intermediate steps included mapping unemployment and renter-occupied units. The spatial pattern in unemployment rates is broadly similar to poverty rates, with higher concentrations in southern SCC and East San Jose. Housing costs are extremely high and rising in this region, making the situation especially difficult for those in low-wage jobs who are seeking affordable housing as displacement becomes increasingly common (Benner and Karner 2016).

In Figs. 4 and 5, we show the results of the FII using the weights in Eq. 1. As expected, the patterns broadly follow the poverty map, with concentrations in central and eastern San Jose and the southern part of SCC; however, the ranges of values of the FII are lower than the poverty only map. The census tract-based assessment identifying the high food insecurity and low access areas (Fig. 5) shows that most areas of high food insecurity have good access to food distribution sites (areas shaded in blue). We calculated that $27 \%$ of the census tracts in SCC have high food insecurity levels (index scores $>16 \%$ ), and that $58 \%$ of the high FII tracts have either good access or some access. The remaining $42 \%$ of the areas have high food insecurity levels and low access (shaded in purple). These areas of concern include the poverty/high food insecurity corridor that is west of Interstate 880/Highway 17, as well as several areas north of 101 and in East Palo Alto.

\section{Comparison of poverty and food insecurity index approaches}

The areas of greatest food assistance need, i.e. high levels of food insecurity and low access, identified by both the FII and the poverty approach share significant spatial overlap (see Fig. 6), although these two metrics produce slightly different estimates regarding the total number of people who are potentially food insecure in SCC. This overlap can be explained by the fact that poverty is the largest factor in the FII (see Eq. 1). In addition to poverty, the two other variables in the FII, unemployment (weighted at $40 \%$ of the index score) and renter-occupied units (weighted at 10\%), were strong enough so that several additional potentially high-need areas omitted by the poverty-only approach were identified (see the purple tracts in Fig. 5 between State Road 85 and Interstate 880 in northern SCC). Both rapid assessment approaches are useful for identifying areas of potential concern, but more research is needed using household surveys to validate the approaches before either approach becomes a standard proxy for estimating the total percent or number of food insecure people.

The poverty-only calculation draws from the $200 \%$ FPL US Census ACS 5-year estimates data from 2010 to 2014 and finds that $23.2 \%$ or 422,004 people in SCC live below the FPL and potentially food insecure. Our FII calculation finds that the average rate of food insecurity is $19.3 \%$ in SCC. Feeding America calculations use the Gundersen (2015) formula to estimate food insecurity levels. They report that in 2013, 12.1\% of the population in SCC was food insecure representing 219,110 people, and in 2011 the calculated rate was 13.4\% (Feeding America 2015).

Although the USDA publishes periodic national studies that use household surveys to measure food insecurity (Coleman-Jensen et al. 2014), we could not find readily available government data that measures and maps the total number of food insecure people at the county, city, and census tract-level in the US. A recently published USDA study drew on a representative sample of more than 42,000 households and found that food insecurity rates in California averaged 13.5\% from 2012 to 2014, down from 16.2\% measured from 2009 to 2011, but still higher than the 2002-2004 average of 12.4\% (Coleman-Jensen et al. 2014: 21). The USDA's direct measures of food insecurity rates in California from 2012 to 14 are slightly below Feeding America's calculation of 15\% in 2013 (Feeding America 2015). The calculation using $200 \%$ of the FPL suggests that food insecurity rates could be significantly above those calculated by Feeding America or those measured by USDA's survey and then generalized to the county level. Our simple FII also yields estimates that are roughly $4 \%$ above the Feeding America estimate, while the poverty-only calculation is about $8 \%$ higher.

Although there are differences in the calculated magnitude of the challenge, the primary goal of this rapid assessment method is to identify areas of potential need. We believe that the patterns of local food insecurity at the census tract-level found using the rapid assessment tools proposed in this study are similar to those calculated by Feeding America if data were available using a finer scale. However, it will be important to use the USDA survey questions during different years and with multiple populations to further test and refine this approach. One key difference between the metrics proposed for this screening method and the Gundersen et al. (2014; 2015) approach is the degree of emphasis or numerical weight placed on poverty levels. The Gundersen et al. models include other important variables, such as unemployment and home ownership; however, their increasingly sophisticated models potentially decrease the influence of poverty rates on predicted food insecurity levels. Recent research using the US Census poverty measure, which includes estimates for the cost of living, finds that California has some of the highest poverty rates in the US (Short 2014). More research is needed to assess how these circumstances influence local determinants of food insecurity, as well as continued work that examines ways in which supplemental food assistance could help keep children and others out of more severe 
forms poverty and high levels of food insecurity (Anderson et al. 2014).

\section{Broader implications}

In addition to contributing to a dialogue about mapping and shared data that document the local determinants and patterns of food insecurity, we argue that this rapid assessment approach can be useful for food banks and charities that coordinate direct food assistance sites and want to ensure they are effectively targeting areas of greatest need. We shared earlier versions of the maps that identify high poverty and low access census tracts (see Figs. 2, 3) with food bank managers, leading to a discussion of how well the food needs of low-income populations were met by current food assistance distribution sites. One immediate result was the addition of another food distribution site in the southern portion of the county. Second Harvest plans to continue working directly with the food assistance providers to encourage them to locate distribution sites in the areas with the greatest unmet needs.

Despite moderate economic growth at the national level, the question of access to food assistance distribution sites by food insecure households remains a pressing one, because the economic gains have not been evenly distributed. The determination of where to locate food assistance sites is complex, especially in large cities or counties where the low-income population is not neatly situated in one or a few densely populated areas. In our research, we found that the highest poverty areas, which were also the most densely populated, had the highest concentration of food assistance sites. However, other high poverty areas, which were less densely populated, had lower levels of access to food assistance distribution sites e.g., several areas in south SCC, especially parts of Gilroy, and a cluster of census tracts located west of Interstate 880 extending from the northern central border of the County west San Jose (see Fig. 5). These areas appear to pose the biggest challenge to food assistance providers. A recently published report confirmed our study's focus on poverty and our findings regarding the importance of additional food assistance in South SCC, finding that the "geographic distribution of homelessness corresponds roughly with the distribution of poverty in SCC, noting that homeless residents are concentrated at the center and south end of the County-in San Jose and Gilroy," and that "Services provided by nonprofit agencies appear to be unevenly distributed, with a below average level of services provided to homeless residents of Gilroy" (Flaming et al. 2015, p. 3).

In the case of food banks, which, in the US, provide the food but do not distribute directly to the clients, the issue of ensuring convenient access and communicating directly with those in need is even more difficult, because they are one step removed from those they serve. The use of GIS can provide insight into the distribution of the impoverished population and the density of that population within census tracts. By overlaying the food distribution sites, we can provide decision makers with easily interpreted visual maps that can be used to evaluate whether their client population has convenient access to the services they offer. This allows managers to see the "big picture" as it relates to the spatial location of food distribution, and is an alternative to separately collecting information and evaluating individual areas to assess their clients' needs and the services provided.

\section{Future research}

Like food desert research, we think that starting an emergency food assistance needs assessment with a rapid mapping approach that focuses on identifying areas of high food insecurity and assessing this population's proximity to food assistance locations is a good first step, but a distancebased analysis needs to be set within a broader context or it risks obscuring how residents cope with food insecurity and other factors that food banks should look at when addressing access. In a previous section of this article, we identify the limits of food access mapping approaches and discuss the complexities of impoverished lives and several food access challenges. In this section, we discuss additional research that could shed light on several questions left unanswered in this paper. For example, why might some of the high-poverty areas not have food assistance distribution sites located nearby? Is it possible that there are food distribution sites located nearby that are not served by the food bank (which provides most of the non-governmental food assistance in the county)? Have the demographic patterns and poverty levels recently changed in these neighborhoods, suggesting the need for other distribution sites? Do people living in these areas have access to good transit, obviating the need for a food assistance distribution site in these neighborhoods? Are there other factors that we have not considered? Answers to these questions require ethnographic research to provide a better understanding of individuals, their situations, behaviors, and activity patterns (Hirsch and Hillier 2013).

The question regarding the ideal location of food distribution sites has two parts. We have attempted to answer the first part, which is, "are there areas with large populations of low-income people who do not have convenient access to a food assistance distribution site?" However, an efficient food assistance distribution network would also ensure that there is not an overabundance of food distribution sites, which could easily occur in areas of high need. Studies focused on welfare assistance have documented welfare 
service hubs, which are likely to host a higher density of the charity-oriented organizations (e.g., churches and social assistance non-profit agencies), which are the same groups that often open food pantries and soup kitchens (DeVerteuil 2015). Thus there is a potential for clustering private food assistance with welfare services in areas such as East San Jose in the present study. Although this could offer some benefits as residents save time by accessing multiple services, the rapidly changing demographic maps of the Silicon Valley and patterns of food insecurity, especially as it relates to rising rents and displacement (Benner and Karner 2016), suggests the need to continually update and re-evaluate spatial location of food assistance in order to meet needs and address issues of spatial equity in regards to accessing benefits (Talen and Anselin 1998).

There are several additional future research projects that could complement this study. We hope to conduct qualitative studies that complement this work and help to develop a more comprehensive understanding of food bank members' everyday lived experiences, and to document the preferences of different racial and ethnic groups. Previous studies suggest the needs for this type of research; for example, a 2003 study used focus groups with food pantry clients and found that "food donations did not match client needs for people with different ethnic backgrounds or age groups and food safety concerns" (Verpy et al. 2003, p. 6). A related study conducted in 2015 , documented food pantry client voices as they expressed appreciation for staff and volunteers, but also concerns about stigma, access to enough food, dietary needs related to specific health conditions (e.g., diabetes), food nutrition, and more (Greer et al. 2016, p. 202). In addition, a future study could use access to national and more detailed local data sets to map patterns in food assistance and need and integrate them with more detailed demographic analysis to match food assistance to a finer scale block group level analysis with a focus on identifying areas that have high concentrations of children, elderly ethnic and racial minorities, or other specific demographic characteristics. Another important future study is food assistance access among Santa Clara County's homeless population. Although SHFB partially addresses this need through partnerships with homeless shelters, shelters account for about $29 \%$ of the estimated homeless population in SCC on any given night, while more than $30 \%$ are in the streets, and 23\% in vehicles (Applied Survey Research 2015), suggesting the need for research and action identifying how to best provide short-term food assistance, even as broader efforts to improve access to housing and other forms of care continue (see the Health Trust's innovative work http://destinationhomescc.org/).

Finally, we wish to include a short reflection on how our own ethics, politics and values relate to the conduct of this type research, consisting of collaboration with food banks to target unmet need, while simultaneously raising questions and starting work to address hunger's root causes. In an insightful article, Cloke, May and Williams start developing a theoretical framework useful for explaining our approach and future research aspirations. "Though also sometimes positioned as a relatively benign, if limited, response to the victims of austerity, the typical starting point for geographical analyses of food banking has been to apply either a food security or political economy perspective" (Cloke et al. 2016, p. 3). The food security argument focuses on the right to food and the inadequacy of food bank offerings, while the political economy critique focuses on how food banks may - inadvertently - further embed private food assistance from the same industrial food system that produces food insecurity, thus legitimizing the structure of the current food system and private donations as an adequate (ethical or politically acceptable) response to hunger (Poppendieck 1999; Williams et al. 2016). In the space between these two critiques, Cloke and colleagues trace "some alternative ways of understanding food banking [including soup kitchens and food pantries], conceptualizing food banks as spaces of care that potentially serve to articulate a newly emerging and not yet fully formed ethical and political response to welfare in the meantime", as they propose to improve strategies to address "the austere conditions of the here and now," while conducting the work, research, and critical reflection that aim to develop more transformative alternatives (Cloke et al. 2016, p. 2).

As engaged researchers, the authors are also concerned about the extent that developing tools to facilitate private food assistance relates to the broader challenge of fulfilling a human right to food, which still lacks political recognition in the US (Dowler and O'Connor 2012). However, the fact that $14 \%$ of the people in the US visited a food bank last year suggests the need to continue improving food assistance as society strives to address this symptom, even as parallel efforts take aim at the root causes. We argue that the analysis in this paper focuses on identifying a more socially just and efficient allocation of scarce resources, which is critical for resource-strapped aid agencies if they are to ensure that their resources go as far as possible. In this way, our study could be seen as a first step—not a final destination - and a proposal to more fairly allocate resources in the shorter term.

Many food bank managers, food justice advocates, and researchers remain profoundly motivated by developing a response that seeks to address longer term challenges related to persistent food insecurity, and this study takes one of the several initial steps by developing a mapping methodology that identifies and prioritizes areas of high poverty and low access to private food assistance. Next steps could also include studies that focus on the role of food banks and partners (e.g., universities, businesses, 
nonprofits) in the innovation processes that aim to build a more equitable and inclusive food systems that enhance healthy food access for all.

Several examples of potentially innovative initiatives to address food insecurity with vulneraby populations from within the study area include efforts that work with low-income seniors, Latino immigrants, and homeless populations. La Mesa Verde is community-based organization that works with low-income Latinos/as to build backyard vegetable gardens, increase food access, and strengthen community ties (Gray et al. 2014; Algert et al. 2016). The Health Trust is leading another local example that recently produced a sophisticated report combining GIS analysis by Fulfrost \& Associates with social research by Calise and Bateman to suggest strategies to better target food assistance serving two of San Jose's most vulnerable populations, low-income seniors and homeless individuals. In addition to identifying areas within San Jose needing additional attention, this report's top recommendations include the need to integrate food access into City and County homeless support services, create a flexible congregate meal system for individuals that are homeless that can move as the population moves, develop senior nutrition programs for the county's estimated $27 \%$ of seniors that are food insecure, create costeffective options in communities with high concentrations of low-income seniors exploring options, such as congregate meal sites or restaurant vouchers, grocery delivery services, and expand SNAP enrollments among both populations (Health Trust 2015, p. 2, 3).

We will also review several related experiences from outside the study area in which private food assistance organizations are simultaneously working to reduce food insecurity, and address longer-term solutions. A statewide food bank claims, "In order to truly end hunger, we need to engage the whole community to develop innovative solutions that address the root causes of hunger. For the last 15 years, Oregon Food Bank has been at the forefront of the development of one of these solutions: building community-based food systems" (Oregon Food Bank 2016). Other examples potentially include the Stop Community Food Centre in Canada, the Matthew Tree Project in Bristol UK, which is an emergency provider that builds trust to develop a holistic response of care that addresses people's multiple challenges, and the many Sikh Langars or free kitchens in India, some of which peacefully and respectfully serve 60,000-100,000 hot meals daily (Gottlieb and Joshi 2013). Research and learning exchanges to assess impacts and social processes that generated these alternative approaches that incorporate private food assistance into broader strategies for creating an inclusive society and reducing hunger are urgently needed.

\section{Conclusions}

The rapid rise in the number of food banks in the US, the UK, Australia and other high-income countries suggests the need for greater attention to how food insecurity needs can be quickly measured, mapped and matched with access to food assistance. In this study we use GIS, readily available demographic data, and Second Harvest food distribution locations to develop a rapid assessment tool. Our findings suggest that food assistance distribution locations match the areas of greatest potential need in more than $80 \%$ of urban census tracts and all of the rural tracts. However, there are several potentially underserved locations that could benefit from new food assistance operations. Food assistance could expand in these areas through partnerships with government social service agencies, as well as community and faith-based institutions serving hot meals with dignity. The maps developed using the poverty-only and food security index-based approaches show significant spatial overlap in the areas of high food insecurity and low access. The poverty-only approach produces a higher estimate of food insecurity rates, is easier to calculate, and highlights poverty as the key driver of food insecurity.

Acknowledgements We are grateful for the insightful comments offered by two anonymous reviewers and thankful to our colleagues at Second Harvest Food Bank of Santa Clara and San Mateo Counties, including Michael Enos, Cindy McCown, and Paul Meagher for providing useful feedback on earlier drafts and access to data. Many thanks to student research assistants William Burke, Michael Lewin, Courtney Robinson, and Jennifer Laws for their diligent work. Lauren Cloward used GIS to help with the final quantitative analysis and produce the maps. The Food and Agribusiness Institute in the Leavey School of Business at Santa Clara University provided funding for this research.

Open Access This article is distributed under the terms of the Creative Commons Attribution 4.0 International License (http:// creativecommons.org/licenses/by/4.0/), which permits unrestricted use, distribution, and reproduction in any medium, provided you give appropriate credit to the original author(s) and the source, provide a link to the Creative Commons license, and indicate if changes were made.

\section{Technical appendix}

See Table 1. 


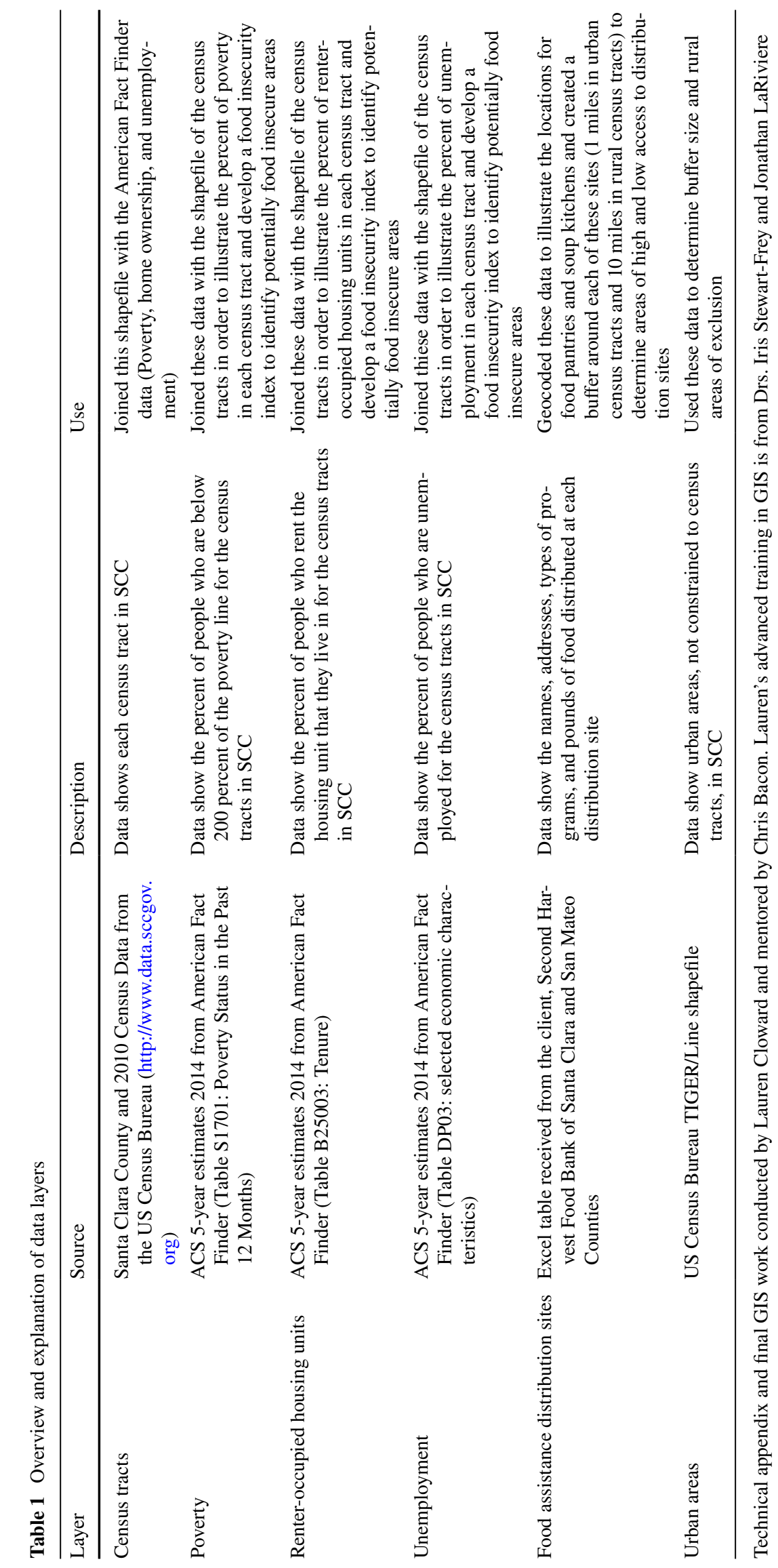




\section{References}

Algert, S., L. Diekmann, M. Renvall, and L. Gray. 2016. Community and home gardens increase vegetable intake and food security of residents in San Jose, California. California Agriculture 70 (2): $77-82$.

Alkon, A.H., D. Block, K. Moore, C. Gillis, N. DiNuccio, and N. Chavez. 2013. Foodways of the urban poor. Geoforum 48: 126-135.

Allard, S.W. 2008. Out of reach: place, poverty, and the new American welfare state. New Haven: Yale University Press.

Anderson, P., K. Butcher, H. Hoynes, and D. Schanzenbach. 2014. Beyond income: what else predicts very low food security among children? University of Kentucky Center for Poverty Research Discussion Paper Series, DP 2014-06.

Applied Survey Research. 2015. Santa Clara County Homeless Census \& Survey. San José, CA.

Bacon, C.M., W.A. Sundstrom, M.E.F. Gómez, V.E. Méndez, R. Santos, B. Goldoftas, and I. Dougherty. 2014. Explaining the 'hungry farmer paradox': smallholders and fair trade cooperatives navigate seasonality and change in Nicaragua's corn and coffee markets. Global Environmental Change 25: 133-149.

Bazerghi, C., F.H. McKay, and M. Dunn. 2016. The role of food banks in addressing food insecurity: Asystematic review. Journal of Community Health, 41 (4): 732-740.

Benner, C. and A. Karner. 2016. Low-wage jobs-housing fit: identifying locations of affordable housing shortages. Urban Geography, 37: 1-21.

Cabili, C., E. Eslami, and R. Briefel. 2013. White Paper on the Emergency Food Assistance Program (TEFAP). Alexandra, VA: U.S. Department of Agriculture, Food and Nutrition Service, Office of Policy Support.

Cloke, P., J. May, and A. Williams. 2016. The geographies of food banks in the meantime. Progress in Human Geography 1-24.

Coleman-Jensen, A., C. Gregory and A. Singh. 2014. Household food security in the United States in 2013. USDA-ERS Economic Research Report 173. http://www.ers.usda.gov/media/1565415/ err173.pdf. Accessed 25 March 2015.

Daponte, B.O., and S. Bade. 2006. How the private food assistance network evolved: Interactions between public and private responses to hunger. Nonprofit and Voluntary Sector Quarterly 35 (4): 668-690.

Desmond, M. 2015. Severe deprivation in America: An introduction. The Russell Sage Foundation Journal of the Social Sciences 1 (1):1-11.

DeVerteuil, G. 2015. Resilience in the post-welfare inner city: Voluntary sector geographies in London, Los Angeles and Sydney. Bristol: Policy Press.

Dowler, E.A., and D. O'Connor. 2012. Rights-based approaches to addressing food poverty and food insecurity in Ireland and UK. Social Science \& Medicine 74(1):44-51.

Drèze, J., and A. Sen. 1989. Hunger and Public action. Oxford: Oxford University Press.

Feagan, R. 2007. The place of food: mapping out the 'local' in local food systems. Progress in Human Geography 31 (1): 23-42.

Feeding America. 2014. Feeding America 2014 Annual Report. http://www.feedingamerica.org/about-us/about-feeding-america/ annual-report/2014-annual-report.pdf. Accessed 25 March 2015.

Feeding America. 2015. Map the Meal Gap. http://map.feedingamerica.org/county/2013/overall. Accessed 1 September 2015.

Feeding America. 2016. How we got the map data. http://www. feedingamerica.org/hunger-in-america/our-research/map-themeal-gap/how-we-got-the-map-data.html?referrer=http:// map.feedingamerica.org/county/2013/overall/california/ county/santa-clara?referrer=http://www.feedingamerica.org/ hunger-in-america/our-research/map-the-meal-gap/how-we-gotthe-map-data.html. Accessed 3-19-2016.

Flaming, D.J., H. Toros, and P. Burns. 2015. Home not found: The cost of homelessness in silicon valley. Santa Clara County, CA: The Economic Roundtable.

González-Torre, P.L., and J. Coque. 2016. How is a food bank managed? Different profiles in Spain. Agriculture and Human Values 33 (1): 89-100.

Goodman, M.K. 2016. Food geographies I Relational foodscapes and the busy-ness of being more-than-food. Progress in Human Geography 40 (2): 257-266.

Gordon-Larsen, P., M.C. Nelson, P. Page, and B.M. Popkin. 2006. Inequality in the built environment underlies key health disparities in physical activity and obesity. Pediatrics 117 (2): $417-424$.

Gordon, C., M. Purciel-Hill, N.R. Ghai, L. Kaufman, R. Graham, and G. Van Wye. 2011. Measuring food deserts in New York City's low-income neighborhoods. Health \& Place 17 (2): 696-700.

Gottlieb, R., and A. Joshi. 2013. Food Justice. Cambridge, MA: MIT Press.

Gray, L., P. Guzman, K.M. Glowa, and A.G. Drevno. 2014. Can home gardens scale up into movements for social change? The role of home gardens in providing food security and community change in San Jose, California. Local Environment 19 (2): 187-203.

Greer, A.E., B. Cross-Denny, M. McCabe, and B. Castrogivanni. 2016. Giving economically disadvantaged, minority food pantry patrons' a voice: Implications for equitable access to sufficient, nutritious food. Family \& Community Health: The Journal of Health Promotion \& Maintenance 39 (3): 199-206.

Gundersen, C., B. Kreider, and J. Pepper. 2011. The Economics of Food Insecurity in the United States. Applied Economic Perspectives and Policy 33 (3): 281-303.

Gundersen, C., E. Engelhard, and E. Waxman. 2014. Map the meal gap: Exploring Food Insecurity at the Local Level. Applied Economic Perspectives and Policy 36 (3): 373-386

Gundersen, C., A. Satoh, A. Dewey, M. Kato, and E. Engelhard. 2015. Map the Meal Gap 2015: Technical Brief. Feeding America.

Guthman, J. 2008. Bringing good food to others: Investigating the subjects of alternative food practice. Cultural Geographies 15 (4): 431-447.

Guthman, J. 2011. Weighing in: Obesity, food justice, and the limits of capitalism. Berkeley, CA: University of California Press.

Harder, C., T. Ormsby, and T. Balstrøm. 2013. Understanding GIS: An ArcGIS Project Workbook. Redlands, CA: ESRI, p. 227.

Health Trust. (2015). Food for Everyone: Food access challenges for low income seniors and homeless individuals in San Jose. Health Trust. http://healthtrust.org/food-for-everyone/ Accessed 7 March 2017.

Hirsch, J.A., and A. Hillier. 2013. Exploring the role of the food environment on food shopping patterns in Philadelphia, PA, USA: A semiquantitative comparison of two matched neighborhood groups. International Journal of Environmental Research and Public Health 10 (1): 295-313.

Hoynes, H.W., E. Bronchetti, and G. Christensen. 2017. The Real Value of SNAP Benefits and Health Outcomes. GSPP Working Paper, University of Kentucky.

Jensen, H. 2002. Food insecurity and the food stamp program. American Journal of Agricultural Economics 84 (5): 1215-1228.

Jyoti, D.F., E.A. Frongillo, and S.J. Jones. 2005. Food insecurity affects school children's academic performance, weight gain, and social skills. The Journal of Nutrition 135 (12): 2831-2839.

Lambie-Mumford, H. 2013. 'Every town should have one': Emergency food banking in the UK. Journal of Social Policy 42 (1): 73-89. 
Lambie-Mumford, H., and E. Dowler. 2014. Rising use of "food aid" in the United Kingdom. British Food Journal 116 (9): $1418-1425$.

Larson, N.I., M.T. Story, and M.C. Nelson. 2009. Neighborhood environments: Disparities in access to healthy foods in the US. American Journal of Preventive Medicine 36 (1): 74-81.

LeClair, M.S., and A.M. Aksan. 2014. Redefining the food desert: Combining GIS with direct observation to measure food access. Agriculture and Human Values 31 (4): 537-547.

Loopstra, R, A. Reeves, D. Taylor-Robinson, B. Barr, M. McKee, D. Stuckler. 2015. Austerity, sanctions, and the rise of food banks in the UK. BMJ (Clinical Research Ed) 350: h1775.

McIntyre, L, D. Tougas, K. Rondeau, and C.L. Mah. 2016. "In"sights about food banks from a critical interpretive synthesis of the academic literature. Agriculture and Human Values 33 (1): 843-859.

McKinnon, R.A., J. Reedy, M.A. Morrissette, L.A. Lytle, and A.L. Yaroch. 2009. Measures of the food environment: A compilation of the literature, 1990-2007. American Journal of Preventive Medicine 36 (4): S124-S133.

Miewald, C., and E. McCann. 2014. Foodscapes and the geographies of poverty: Sustenance, strategy, and politics in an urban neighborhood. Antipode 46 (2): 537-556.

Minkoff-Zern, L.A. 2014a. Hunger amidst plenty: Farmworker food insecurity and coping strategies in California. Local Environment 19 (2): 204-219.

Minkoff-Zern, L.A. 2014b. Knowing "good food": Immigrant knowledge and the racial politics of farmworker food insecurity. Antipode 46 (5): 1190-1204.

Nellum, N. 2015. Fighting food insecurity on campus. Higher Education Today. http://higheredtoday.org/2015/06/29/fighting-foodinsecurity-on-campus/. Accessed 24 March 2016.

Oregon Food Bank. 2016. Our Work. https://www.oregonfoodbank. org/our-work/partnerships/community-food-systems/ Accessed 12 Dec 2016.

Paynter, S., M. Berner, and E. Anderson. 2011. When even the 'dollar value meal 'costs too much: Food insecurity and long term dependence on food pantry assistance. Public Administration Quarterly 35 (3): 26-58.

Perry J, M. Williams, T. Sefton, M. Haddad. 2014. Emergency use only: Understanding and reducing the use of food banks in the UK. Accessed 22 Feb 2016. http://policy-practice.oxfam.org.uk/ publications/emergency-use-only-understanding-and-reducingthe-use-of-food-banks-in-the-uk-335731.

Popkin, S.J., M. Scott, M Galvez. 2016. Impossible Choices Teens and Food Insecurity in America. Urban Institute and Feeding America. http://www.urban.org/research/publication/ impossible-choices-teens-and-food-insecurity-america.

Poppendieck, J. 1999. Sweet charity?: Emergency food and the end of entitlement. Penguin.

Purdam, K., E.A. Garratt, and Esmail, A. 2015. Hungry? Food insecurity, social stigma and embarrassment in the UK. Sociology, $1-17$.

Schmidt, L., L. Shore-Sheppard, and T. Watson. 2013. The Effect of Safety Net Programs on Food Insecurity. Working Paper 19558. National Bureau of Economic Research. http://www.nber.org/ papers/w19558.pdf. Accessed 12 November 2015.

Second Harvest Food Bank of Santa Clara and San Mateo Counties. 2013. Spreadsheet of food Assistance distribution locations in Santa Clara County.

Shannon, J. 2013. Food deserts Governing obesity in the neoliberal city. Progress in Human Geography 38 (2): 248-266.

Short, A., J. Guthman, and S. Raskin. 2007. Food deserts, oases, or mirages? Small markets and community food security in the
San Francisco Bay Area. Journal of Planning Education and Research 26 (3): 352-364.

Short, K. 2014. The supplemental poverty measure: 2013. Current Population Reports. US Census. Available at: https://www. census.gov/content/dam/Census/library/publications/2014/ demo/p60-251.pdf?eml=gd\&utm_medium=email\&utm_ source=govdelivery. Accessed 15 March 2017.

Talen, E., and L. Anselin. 1998. Assessing spatial equity: An evaluation of measures of accessibility to public playgrounds. Environment and Planning A 30 (4): 595-613.

Tarasuk, V., N. Dachner, and R. Loopstra. 2014. Food banks, welfare, and food insecurity in Canada. British Food Journal, 116 (9): $1405-1417$.

Tsang, S., A.M. Holt, and E. Azevedo. 2011. An assessment of the barriers to accessing food among food-insecure people in Cobourg, Ontario. Chronic Diseases and Injuries in Canada, 31 (3): 121-128.

US Census Bureau. 2014a. US Census Quickfacts. Bureau. http:// www.census.gov/quickfacts/table/PST045214/06085,06081. Accessed 1 October 2015.

US Census Bureau. 2014b. US Census Quickfacts. Bureau. http:// quickfacts.census.gov/qfd/states/06/06085.html. Accessed 1 October 2015.

US Census Bureau. 2015. American Community Survey. 2010 to 2014 American Community Survey 1-Year Estimates; generated by Lauren Cloward; using American FactFinder. http:// factfinder2.census.gov. Accessed 1 March 2016.

USDA. 2015. Food Access Research Atlas. http://www.ers.usda.gov/ data-products/food-access-research-atlas/documentation.aspx. Accessed 1 March 2016.

USDA, ERS. 2009. Access to affordable and nutritious food: measuring and understanding food deserts and their consequences. http://www.ers.usda.gov/media/242675/ap036_1_.pdf. Accessed 1 September 2015.

USDA, Food and Nutrition Service. 2015. Data: Overview: Summary of Annual Data, FY 2010-2014. http://www.fns.usda.gov/pd/ overview. Accessed 25 March 2015.

Verpy, H., C. Smith, and M. Reicks. 2003. Attitudes and behaviors of food donors and perceived needs and wants of food shelf clients. Journal of Nutrition Education and Behavior 35 (1): 6-15.

Widener, M.J., and J. Shannon. 2014. When are food deserts? Integrating time into research on food accessibility. Health \& Place 30: 1-3.

Wilde, P., J. Llobrera, and M. Ver Ploeg. 2014. Population density, poverty, and food retail access in the United States: An empirical approach. International Food and Agribusiness Management Review. 17 (A).

Will, J.A., and T.A. Milligan 2015. Toward an understanding of food pantry food recipients and the agencies that serve them. Journal of Applied Social Science 9 (1): 65-74.

Williams, A., P. Cloke, J. May, and M. Goodwin. 2016. Contested space: The contradictory political dynamics of food banking in the UK. Environment and Planning A 3 (11): 2291-2310.

Christopher M. Bacon, PhD is an Associate Professor of Environmental Studies and a Bannan Faculty Fellow for Environmental Justice and the Common Good at Santa Clara University. His work focuses on agrarian change, food security and agroecology in Latin America and the Caribbean, and environmental and food justice in California. The major focus of his research utilizes community-based participatory action research partnerships formed with smallholders, cooperatives, and other local institutions to explain and improve access to culturally preferred food and clean drinking water in the context of global change in Nicaragua. 
Gregory A. Baker, PhD is a Professor of Management and Director of the Food and Agribusiness Institute at Santa Clara University. His current research includes food security, measuring food waste at the farm level, the effectiveness of front-of-package food labels, and the impacts of urban agriculture. He holds the Naumes Family Endowed Chair at Santa Clara University and is a Fellow of the International Food and Agribusiness Management Association. 